\title{
A study on water-mass-to-collector-area ratio for the flat-plate solar water heating system used in Yunnan Province
}

\author{
Shengxian $\mathrm{Wei}^{1, \mathrm{a}}$, Fene $\mathrm{Hu}^{2}$ and ${\mathrm{Zhe} \mathrm{Li}^{1}}^{1}$ \\ ${ }^{1}$ College of Physics and Electronic Engineering, Qujing Normal University, Qujing 655011, China; \\ ${ }^{2}$ College of Chemistry and Chemical Engineering, Qujing Normal University, Qujing 655011, China. \\ ${ }^{\mathrm{a} C}$ Corresponding author: wsx_8600@163.com
}

Keywords: Solar water heating system; MAR; Flat-plate solar collector; Optimal tilt angle

\begin{abstract}
The model for calculating the water-mass-to-collector-area ratio (the ratio is abbreviated as MAR) was developed based on the useful energy output model of a flat-plate solar collector. The MARs were calculated by using the typical meteorological data of seven cities in Yunnan Province. The final water temperature of the water tank is assumed to be $60^{\circ} \mathrm{C}$ during the calculation. The ranges of MARs have been given for seasonal or year-round running of the flat-plate solar water heating system. For convenient engineering applications, the quadratic fit equations between MARs and tilt angles have been obtained with high correlations $\left(\mathrm{R}^{2}>0.999\right)$. Further discussions found that the optimal tilt angles and the corresponding MARs for spring, summer, autumn, winter or year-round operation of the solar water heating system are respectively in $10 \sim 15^{\circ}, 0 \sim 0^{\circ}, 32 \sim 38^{\circ}, 45 \sim 50^{\circ}, 24$ $\sim 30^{\circ}, 50 \sim 60 \mathrm{~kg} / \mathrm{m}^{2}, 44 \sim 51 \mathrm{~kg} / \mathrm{m}^{2}, 43 \sim 56 \mathrm{~kg} / \mathrm{m}^{2}, 44 \sim 58 \mathrm{~kg} / \mathrm{m}^{2}$ and $46 \sim 52 \mathrm{~kg} / \mathrm{m}^{2}$.
\end{abstract}

\section{Introduction}

Matching problem of the mass of water in the tank and collector area is one of the key problems of solar hot water system. To insure the high-efficiency operation of the solar water heating system and meet the water temperature requirement of the consumers, the different water-mass-to-collector-arearatios (the ratio is abbreviated as MAR) have been recommended in different climatic regions at home and abroad. The values of the MAR in America [1] and Greece [2] are $75 \mathrm{~kg} / \mathrm{m}^{2}$. The value of MAR in Malaysia [3] is $50-70 \mathrm{~kg} / \mathrm{m}^{2}$ and in China [4] is less than $100 \mathrm{~kg} / \mathrm{m}^{2} .60-100 \mathrm{~kg} / \mathrm{m}^{2}$ are recommended in Kunming for the flat-plate solar water heating system while the daily thermal efficiency and the end water temperature in water tank are more than 0.45 and $45^{\circ} \mathrm{C}$ [5].

However, the range of the above MARs is large and is difficult to determine the values of the MAR of the solar water heating system used in different climatic regions. To solve this problem, the calculation model of the MAR of the solar water heating system has been built based the useful energy output model of the flat-plate solar collector. Previous studies have verified that the relative error of the calculated and measured values is within 10\% [6]. The MARs were calculated by using the typical meteorological data of seven cities in Yunnan Province. During the discussions, the final water temperature in the tank is $60{ }^{\circ} \mathrm{C}$ and the azimuth angle of the solar collector is $0^{\circ}$. For ease of engineering applications, the relationships between the MARs and the tilt angles have been obtained for spring, summer, autumn, winter or year-round operation of the solar water heating system. In addition, the optimal tilt angles and the corresponding MARs have been given for the optimization design of the flat-plate solar hot water system.

\section{Mathematical model}

Energy output model of the flat-plate solar collector. The hourly total solar radiation $I_{\beta}$ on the unit inclined plane can be expressed as [7]:

$$
I_{\beta}=K_{\mathrm{b}} I_{\mathrm{b}} \cos \theta+\frac{1}{3} K_{\mathrm{d}} I_{\mathrm{d}}(2+\cos \beta)+\frac{1}{2} \rho_{\mathrm{g}} K_{\mathrm{g}} I_{\mathrm{h}}(1-\cos \beta)
$$


where $I_{\mathrm{b}}, I_{\mathrm{d}}$ and $I_{\mathrm{h}}\left(I_{\mathrm{h}}=I_{\mathrm{b}}+I_{\mathrm{d}}\right)$ are respectively hourly beam, diffuse and total solar radiation on the horizontal plane. $\beta$ is the tilt angle and $\rho_{\mathrm{g}}$ is the reflectivity of ground. The incidence angle modifiers $K_{\mathrm{b}}, K_{\mathrm{d}}$ and $K_{\mathrm{g}}$ [8] are given by $K_{\mathrm{b}}=1+b_{0}(1 / \cos \theta-1), K_{\mathrm{d}}=1+b_{0}\left(1 / \cos \theta_{\mathrm{d}}-1\right)$ and $K_{\mathrm{g}}=1+b_{0}\left(1 / \cos \theta_{\mathrm{g}}-1\right)$. For a single glass cover, $b_{0}=0.1$. The equivalent incident angles $\left(\theta, \theta_{\mathrm{d}}\right.$ and $\left.\theta_{\mathrm{g}}\right)$ of the beam, diffuse and ground reflection radiation are calculated by $\cos \theta=\sin \delta \sin (\lambda-\beta)+\cos \delta \cos (\lambda-\beta) \cos \omega, \theta_{d}=59.68$ $0.1388 \beta+0.001497 \beta^{2}$ and $\theta_{\mathrm{g}}=90-0.5788 \beta+0.002693 \beta^{2} . \delta, \lambda$ and $\omega$ are the solar declination angle, the geographic latitude and the hour angle.

The energy output $\left(\mathrm{Q}_{\mathrm{u}}\right)$ of a flat-plate solar collector under steady-state conditions can valued as

$$
Q_{\mathrm{u}}=A_{\mathrm{c}} \int_{t_{1}}^{t_{2}}\left[(\tau \alpha) I_{\beta}-U_{\mathrm{Lf}}\left(T_{\mathrm{abs}}-T_{\mathrm{air}}\right)\right] d t
$$

where $t_{1}$ and $t_{2}$ are the beginning time and the end time. Ac is the collector area, $(\tau \alpha)$ is the transmission- absorption product, $\mathrm{T}_{\mathrm{abs}}$ and $\mathrm{T}_{\text {air }}$ are the heat-absorption plate temperature and ambient air temperature. The heat loss coefficient $\left(U_{\mathrm{Lf}}\right)$ of the solar collector can be described as $U_{\mathrm{Lf}}=$ $U_{\text {top }}+U_{\text {bot }}+U_{\text {edg. }} U_{\text {top }}$ is the top heat loss coefficient [9], $U_{\text {bot }}$ and $U_{\text {edg }}$ are the bottom and edge heat loss coefficients [10].

Water-mass-to-collector-area ratio (MAR). The heat consumption $\left(Q_{\mathrm{h}}\right)$ of the hot water is determined by the following formula

$$
Q_{h}=M C_{\mathrm{p}}\left(T_{\text {hot }}-T_{\mathrm{w}}\right)
$$

where $M$ is the water mass in the tank, $C_{\mathrm{p}}$ is the specific heat of water, $T_{\text {hot }}$ is water temperature for use and $T_{\mathrm{w}}$ is the water temperature of the city water. When $Q_{\mathrm{u}}=Q_{\mathrm{h}}$, the energy output of the solar water heating system can meet the heat load for hot water supply. Then, the MAR can be indicated as

$$
\frac{M}{A_{c}}=\frac{\int_{t_{1}}^{t_{2}}\left[(\tau \alpha) I_{\beta}-U_{\mathrm{Lf}}\left(T_{\text {abs }}-T_{\text {air }}\right)\right] d t}{C_{\mathrm{p}}\left(T_{\text {hot }}-T_{\mathrm{w}}\right)}
$$

Due to the lack of water temperature data, the water temperature of the city water can be estimated by the empirical formulas [11,12]:

$$
T_{\mathrm{w}}=\frac{1}{2}\left(\left(2.82+0.82 T_{\text {air }}\right) \frac{\left(1+R_{h}^{2}\right)^{0.435}}{\left(1+0.31 V^{2}\right)^{0.056}}+4.717 e^{0.041 T_{\text {air }}} \frac{\left(1+R_{h}^{2}\right)^{0.781}}{\left(1+0.325 V^{2}\right)^{0.0325}}\right)
$$

where $R_{\mathrm{h}}$ is the relative humidity and $V$ is the wind velocity.

\section{Calculations and discussions of MAR}

The MARs have been calculated based on the typical meteorological data of seven cities (Mengzi, Lincang, Tengchong, Kunming, Chuxiong, Lijiang and Deqin) in Yunnan Province. During the simulation, the ransmission-absorption product $(\tau \alpha)$ is 0.81 , the albedo of ground $\left(\rho_{\mathrm{g}}\right)$ is 0.2 and the specific heat of water $\left(\mathrm{C}_{\mathrm{p}}\right)$ is $4.187 \mathrm{~kJ} /(\mathrm{kg} \cdot \mathrm{K})$.

Table 1 Ranges of MARs for seasonal or year-round running of flat-plate solar hot water system

\begin{tabular}{lllllll}
\hline City & Latitude $\left({ }^{\circ}\right)$ & Spring & Summer & Autumn & Winter & Year-round \\
\hline Mengzi & 23.38 & $28.6 \sim 55.5$ & $22.3 \sim 50.2$ & $34.0 \sim 48.6$ & $43.1 \sim 55.1$ & $32.1 \sim 50.8$ \\
Lincang & 23.88 & $28.9 \sim 56.0$ & $22.5 \sim 48.9$ & $37.0 \sim 52.7$ & $44.4 \sim 58.0$ & $33.6 \sim 52.3$ \\
Tengchong & 25.02 & $28.1 \sim 52.1$ & $21.8 \sim 44.8$ & $40.0 \sim 56.2$ & $42.9 \sim 57.5$ & $34.1 \sim 51.1$ \\
Kunming & 25.02 & $31.4 \sim 59.2$ & $21.8 \sim 46.8$ & $30.8 \sim 43.1$ & $41.6 \sim 54.6$ & $31.9 \sim 49.5$ \\
Chuxiong & 25.03 & $28.0 \sim 51.4$ & $21.4 \sim 44.1$ & $33.3 \sim 45.9$ & $40.6 \sim 53.2$ & $31.3 \sim 47.3$ \\
Lijiang & 26.87 & $28.1 \sim 53.1$ & $21.6 \sim 47.9$ & $35.1 \sim 47.7$ & $41.1 \sim 57.9$ & $33.0 \sim 49.9$ \\
Deqin & 28.48 & $28.0 \sim 49.6$ & $24.0 \sim 48.2$ & $35.0 \sim 47.7$ & $32.8 \sim 44.2$ & $30.9 \sim 46.1$ \\
\hline
\end{tabular}

For the tilt angle variation from $0^{\circ}$ to $90^{\circ}$, the ranges of MARs for seasonal or year-round operation of solar water heating system are given in Table 1 . The data in Table 1 show that the ranges of the 
MARs for spring, summer, autumn, winter and year-round are respectively in $28 \sim 59 \mathrm{~kg} / \mathrm{m}^{2}, 21 \sim 50$ $\mathrm{kg} / \mathrm{m}^{2}, 30 \sim 56 \mathrm{~kg} / \mathrm{m}^{2}, 32 \sim 58 \mathrm{~kg} / \mathrm{m}^{2}$ and $30 \sim 52 \mathrm{~kg} / \mathrm{m}^{2}$. The ranges are lightly large and difficult to determine the effective value of MARs for the design of the solar hot water system. For convenient engineering applications, the relationships between the MARs and tilt angles have been analyzed by using the nonlinear quadratic fit method (i.e. Equation (6)). Regression coefficients ( $a, b$ and c) and correlation coefficients $\left(\mathrm{R}^{2}\right)$ of equation (6) are shown in Table 2 .

$$
M A R=a+b \beta+c \beta^{2}
$$

Table 2 Regression coefficients and correlation coefficients of equation (6)

\begin{tabular}{llrrrrrrr}
\hline \multirow{5}{*}{ Spring } & & Mengzi & Lincang & Tengchong & Kunming & Chuxiong & Lijiang & \multicolumn{1}{c}{ Deqin } \\
\hline \multirow{6}{*}{ Summer } & $a$ & 55.0871 & 55.5406 & 51.5238 & 58.1038 & 50.7145 & 52.0176 & 48.7252 \\
& $b$ & 0.0803 & 0.0848 & 0.0934 & 0.1367 & 0.0980 & 0.1288 & 0.1064 \\
& $c$ & -0.0042 & -0.0043 & -0.0040 & -0.0049 & -0.0039 & -0.0044 & -0.0038 \\
& $R^{2}$ & 0.9991 & 0.9991 & 0.9991 & 0.9991 & 0.9991 & 0.9991 & 0.9991 \\
& $a$ & 50.6336 & 49.2748 & 45.1026 & 47.1577 & 44.3682 & 48.2826 & 48.4826 \\
& $b$ & -0.0617 & -0.0515 & -0.0361 & -0.0433 & -0.0384 & -0.0307 & -0.0162 \\
Autumn & $R^{2}$ & -0.0029 & -0.0028 & -0.0025 & -0.0027 & -0.0025 & -0.0030 & -0.0029 \\
& $a$ & 43.7942 & 47.0452 & 49.1120 & 38.7895 & 40.5900 & 40.5190 & 41.4646 \\
& $b$ & 0.2893 & 0.3341 & 0.3956 & 0.2581 & 0.3023 & 0.3675 & 0.3350 \\
\multirow{5}{*}{ Winter } & $c$ & -0.0045 & -0.0050 & -0.0055 & -0.0039 & -0.0043 & -0.0048 & -0.0045 \\
& $R^{2}$ & 0.9994 & 0.9994 & 0.9995 & 0.9994 & 0.9995 & 0.9996 & 0.9996 \\
& $a$ & 42.9993 & 44.2734 & 42.7244 & 41.4876 & 40.4962 & 41.2198 & 32.6374 \\
& $b$ & 0.5363 & 0.58945 & 0.6086 & 0.5569 & 0.5406 & 0.6620 & 0.4623 \\
& $c$ & -0.0059 & -0.0063 & -0.0063 & -0.0059 & -0.0058 & -0.0066 & -0.0046 \\
\multirow{5}{*}{ Year-round } & $R^{2}$ & 0.9998 & 0.9998 & 0.9997 & 0.9998 & 0.9998 & 0.9997 & 0.9997 \\
& $a$ & 48.1299 & 49.0306 & 47.1137 & 46.3853 & 44.0426 & 45.5133 & 42.8304 \\
& $b$ & 0.2110 & 0.2393 & 0.2655 & 0.2272 & 0.2255 & 0.2817 & 0.2218 \\
& $c$ & -0.0044 & -0.0046 & -0.0046 & -0.0043 & -0.0041 & -0.0047 & -0.0040 \\
& $R^{2}$ & 0.9992 & 0.9992 & 0.9993 & 0.9992 & 0.9993 & 0.9993 & 0.9993 \\
\hline
\end{tabular}

The data in Table 2 show that the MARs and tilt angle $\beta$ are highly correlated and their correlation coefficients are more than 0.999. Using equation (6) and the coefficients in Table 2, we can quickly determine the MARs for seasonal or year-round running of the solar water heating system in Yunnan Province.

Table 3 Optimal tilt angle and corresponding MARs of the flat-plate solar water heating system

\begin{tabular}{lccccccccccc}
\hline & \multicolumn{2}{c}{ Spring } & \multicolumn{2}{c}{ Summer } & \multicolumn{2}{c}{ Autumn } & \multicolumn{2}{c}{ Winter } & \multicolumn{2}{c}{ Year-round } \\
\cline { 2 - 11 } City & $\begin{array}{c}\beta_{\text {opt }} \\
\left({ }^{\circ}\right)\end{array}$ & $\begin{array}{c}\mathrm{MAR}_{\mathrm{op}} \\
\left(\mathrm{kg} / \mathrm{m}^{2}\right)\end{array}$ & $\begin{array}{c}\beta_{\text {opt }} \\
\left({ }^{\circ}\right)\end{array}$ & $\begin{array}{c}\mathrm{MAR}_{\mathrm{op}} \\
\left(\mathrm{kg} / \mathrm{m}^{2}\right)\end{array}$ & $\begin{array}{c}\beta_{\text {opt }} \\
\left({ }^{\circ}\right)\end{array}$ & $\begin{array}{c}\mathrm{MAR}_{\mathrm{op}} \\
\left(\mathrm{kg} / \mathrm{m}^{2}\right)\end{array}$ & $\begin{array}{c}\beta_{\text {opt }} \\
\left({ }^{\circ}\right)\end{array}$ & $\begin{array}{c}\mathrm{MAR}_{\mathrm{op}} \\
\left(\mathrm{kg} / \mathrm{m}^{2}\right)\end{array}$ & $\begin{array}{c}\beta_{\text {opt }} \\
\left({ }^{\circ}\right)\end{array}$ & $\begin{array}{c}\mathrm{MAR}_{\mathrm{op}} \\
\left(\mathrm{kg} / \mathrm{m}^{2}\right)\end{array}$ \\
\hline Mengzi & 9.56 & 55.47 & 0.00 & 50.63 & 32.14 & 48.44 & 45.45 & 55.19 & 23.98 & 50.66 \\
Lincang & 9.86 & 55.96 & 0.00 & 49.27 & 33.41 & 52.63 & 46.78 & 58.06 & 26.01 & 52.14 \\
Tengchong & 11.68 & 52.07 & 0.00 & 45.10 & 35.96 & 56.23 & 48.30 & 57.42 & 28.86 & 50.94 \\
Kunming & 13.95 & 59.06 & 0.00 & 47.16 & 33.09 & 43.06 & 47.19 & 54.63 & 26.42 & 49.39 \\
Chuxiong & 12.56 & 51.33 & 0.00 & 44.37 & 35.15 & 45.90 & 46.60 & 53.09 & 27.50 & 47.14 \\
Lijiang & 14.64 & 52.96 & 0.00 & 48.28 & 38.28 & 47.55 & 50.15 & 57.82 & 29.97 & 49.73 \\
Deqin & 14.00 & 49.47 & 0.00 & 48.48 & 37.22 & 47.70 & 50.25 & 44.25 & 27.73 & 45.91 \\
\hline
\end{tabular}

According to the extreme value conditions $d(M A R) / d \beta=b+2 c \beta=0$ and equation (6), we can obtain the optimal tilt angle $\left(\beta_{\mathrm{opt}}\right)$ and corresponding $\mathrm{MAR}_{\mathrm{opt}}$. And the vales of the $\beta_{\mathrm{opt}}$ and $\mathrm{MAR}_{\mathrm{opt}}$ 
are listed in Table 3. The calculated values of the optimal tilt angle in summer are negative and the tilt angle in this paper is $0-90^{\circ}$. Therefore, the optimal tilt angles in summer are recorded as $0^{\circ}$ in Table 3. The data in Table 3 show that the optimal tilt angles and the corresponding $\mathrm{MAR}_{\mathrm{opt}}$ for spring, summer, autumn, winter or year-round operation of the solar water heating system are respectively in $10 \sim 15^{\circ}, 0 \sim 0^{\circ}, 32 \sim 38^{\circ}, 45 \sim 50^{\circ}, 24 \sim 30^{\circ}, 50 \sim 60 \mathrm{~kg} / \mathrm{m}^{2}, 44 \sim 51 \mathrm{~kg} / \mathrm{m}^{2}, 43 \sim 56 \mathrm{~kg} / \mathrm{m}^{2}, 44 \sim 58 \mathrm{~kg} / \mathrm{m}^{2}$ and $46 \sim 52 \mathrm{~kg} / \mathrm{m}^{2}$.

\section{Results and conclusions}

The calculation model of the water-mass-to-collector-area ratio (MAR) was built based on the useful energy output model of a flat-plate solar collector.

The ranges of the MARs for seasonal or year-round running of flat-plate solar water heating system have been calculated based on the typical meteorological data of seven cities in Yunnan Province.

For convenient engineering application, the relationships between the MARs and tilt angle have been conducted by using quadratic fit method. The results show that the MARs and tilt angles are highly correlated and their correlation coefficients are more than 0.999 .

Further discussions show that the optimal tilt angles and the corresponding $\mathrm{MAR}_{\mathrm{opt}}$ for spring, summer, autumn, winter or year-round operation of the solar water heating system are respectively in $10 \sim 15^{\circ}, 0 \sim 0^{\circ}, 32 \sim 38^{\circ}, 45 \sim 50^{\circ}, 24 \sim 30^{\circ}, 50 \sim 60 \mathrm{~kg} / \mathrm{m}^{2}, 44 \sim 51 \mathrm{~kg} / \mathrm{m}^{2}, 43 \sim 56 \mathrm{~kg} / \mathrm{m}^{2}, 44 \sim 58 \mathrm{~kg} / \mathrm{m}^{2}$ and $46 \sim 52 \mathrm{~kg} / \mathrm{m}^{2}$.

\section{Acknowledgements}

The work was financially supported by the Applied Basic Research Project of the Yunnan Province (Grant No. 2013FZ111), the Project for Innovative Research Team (Grant No. TD201301), the Education Reform Project (Grant No. JGXM2012013) and the Superior Quality Course 'Calorifics' (Grant No. YZKC201408) of the Qujing Normal University.

\section{References}

[1] J.A. Duffie, W.A. Beckman. Solar engineering of thermal processes. New York: John Wiley \& Sons, Inc, 1991.

[2] D. E. PRAPAS. Renewable Energy, 1995,6(4):399-406.

[3] H. R. Zahedi, N.M. Adam, S M Sapuan and M.M.H.M.Ahmad. Journal of Scientific \& Industrial Research, 2007, 66 (2):146-151.

[4] NY/T 343-1998.: Agriculture industry standards of People's Republic of China,1998.

[5] X.X. Chen, W.F. Gao. Journal of Yunnan Normal University, 2000,20(2): 24-28.

[6] S.X. Wei, M. Li, W.X. Lin, et al. Acta Energiae Solaris Sinica, 2012, 33(4): 663-669.

[7] G. Notton, C. Cristofari, P. Poggi. Energy Conversion and Management,2006,47 (2): 147-173.

[8] C. Cristofari, G. Notton, P. Poggi and A. Louche. Solar Energy,2002,72(2):99-112.

[9] S.A. Klein. Solar Energy,1975,17(1):79-80.

[10] H.F. Zhang, J.D. Yu,C.L. Zhao. Solar thermal application principle and Computer Simulation (2nd edition). Xian: Northwestern Polytechnical University Press, 2007.

[11] Z.Y. Bai. Hydrology, 1999,3:29-32.

[12] K.F. Li, H.S. Hao, C.Y. Zhuang. Journal of Sichuan University (Engineering Science Edition) 2006, 38(1):1-4. 